\title{
Experimental study of the effectiveness of a water system in blocking fire-induced smoke and heat in reduced-scale tunnel tests
}

Jiayun Sun ${ }^{1,2}$, Zheng Fang ${ }^{1}$, Zhi Tang $^{1}$, Tarek Beji $^{2}$ and Bart Merci ${ }^{2}$

\section{Abstract}

A water system, consisting of several water mist nozzles, has been installed in a reduced-scale tunnel.

Its effectiveness in blocking fire-induced smoke and heat is tested, with and without longitudinal ventilation. A total of 14 fire tests have been carried out, with $250 \mathrm{ml}$ methanol in an iron tray $(25 \mathrm{~cm} \mathrm{x}$ $20 \mathrm{~cm}$ ) as fuel. Temperatures have been measured by 30 thermocouples, located upstream and downstream of the fire location. The aim is to assess the effectiveness of the water system in preventing smoke spread and in reducing the temperature in the tunnel. Interaction of the water with the fire is avoided. The impact of water pressure, ventilation velocity and nozzle arrangement on the effectiveness in smoke blocking and temperature reduction is discussed. The result confirms that the water system effectively reduces the temperatures and prevents smoke spreading in the absence of longitudinal ventilation. However, strong longitudinal ventilation $(0.8 \mathrm{~m} / \mathrm{s}$ ventilation velocity in the reduced-scale tunnel, corresponding to critical velocity in full-scale (1:10) tunnel) reduces the effectiveness in blocking the smoke spreading by the water system, although the temperature

\footnotetext{
${ }^{1}$ School of Civil Engineering, Wuhan University,Wuhan,Hubei,430072,China

${ }^{2}$ Dept. of Flow, Heat and Combustion Mechanics, Ghent University-UGent, B-9000 Ghent, Belgium 
reduction downstream the water system remains in place. Higher water pressure makes the cooling effect stronger, because more and smaller water droplets are injected into the tunnel. For a given level of water pressure level, the impact of the nozzle row configuration is small in the tests.

\section{Keywords}

Reduced-scale fire tests, tunnel fire, water system, water mist, smoke blocking

\section{Introduction}

In recent years, the interest for fire safety issues in tunnels has increased dramatically due to a significant increase in number of tunnels worldwide and due to numerous catastrophic tunnel fires(Carvel, 2005). As an international agreement (Montreal Protocol) announced that bromine-based

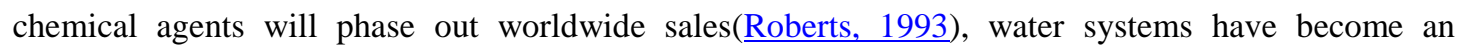
important and interesting field of investigation. A distinction can be made between water mist systems and sprinkler systems, based on the droplet size. In a water mist spray, approximately $90 \%$ of the droplets have a diameter of less than $500 \mu \mathrm{m}$, which is an order of magnitude smaller than in conventional sprinkler sprays (Grant, 2000).

Due to the relatively limited cross-sectional area in tunnels, hot smoke can spread rapidly, e.g., downstream with the traffic flow or due to longitudinal ventilation. Consequently, people downstream of the fire may be exposed to high temperatures and toxic gases, especially in urban tunnels which are likely to clog during rush hours. Inspired by fire compartmentation in buildings, it is worth investigating whether a tunnel can be partitioned by a water system into a fire zone and safety zones. If so, people can move from the fire zone into a safe zone through the water system. Obviously, an essential question is to examine to what extent the fire-induced heat and smoke can be blocked by the water system. 
To date, many research studies have been conducted concerning the use of water mist systems in enclosures (Jenft et al., 2014; Kim and Ryou, 2003; Prasad et al., 2002; Yang et al., 2010). Restricting the survey to water mist in tunnel configurations, experimental and numerical approaches are found on

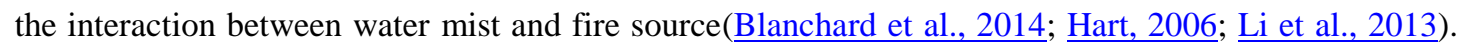

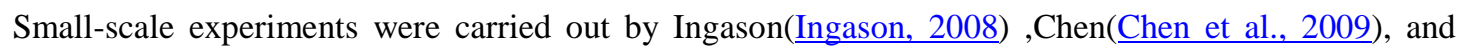
$\mathrm{Li}(\underline{\mathrm{Li} \text { et al., 2013 }})$ on the suppression efficiency between water mist characteristics (water flow rate, mean diameter, spray angle, etc.) and tunnel environment (ventilation condition, heat release rate, etc.). Blanchard(Blanchard et al., 2014) investigated the interaction between hot gases and a water mist system in a model tunnel. Concerning numerical studies, also a few papers can be found(Blanchard et al., 2014; Hart, 2006; Nmira et al., 2009). The original idea of these studies is to discharge the water mist directly on the fire source, so that the heat release rate can be decreased due to the cooling effect through heat absorption by water droplets.

The aim of the present study, on the other hand, is to study the potential use of water mist as a curtain in order to prevent smoke and heat spreading. In other words, the study is not on fire suppression. On the contrary, as explained below, special care has been taken to make sure that the fire heat release rate is not influenced by water mist system during our tests. The effectiveness of the water mist curtain in preventing smoke spreading and in reducing temperatures is described for a naturally and mechanically ventilated tunnel in the present paper.

The use of water curtains in buildings as a boundary of a fire compartment is not new. A real-scale fire experiment, where a water curtain acted as partition to prevent heat and smoke spread to the adjacent room, was performed by W.K. Chow(W.K. Chow, 2011). Also in tunnel configurations, some reduced-scale experiments focused on the prevention of fire $\operatorname{spread}(\underline{\text { Amano et al., 2005) }})^{\text {(Ingason, }}$ 
2008). In this paper a total of 14 fire tests are discussed, involving a parametric study on the efficiency of smoke blocking and temperature reduction, including water mist characteristics and the longitudinal ventilation velocity in the tunnel.

\section{Experimental Setup}

\subsection{Tunnel geometry}

The reduced-scale tunnel is $18 \mathrm{~m}$ long, $1.1 \mathrm{~m}$ wide and $0.4 \mathrm{~m}$ high (Figure 1). It consists of non-combustible, $8 \mathrm{~mm}$ thick fireproof glass (density $2700 \mathrm{~kg} / \mathrm{m}^{3}$, heat conductivity $0.041 \mathrm{~W} /(\mathrm{m} \cdot \mathrm{K})$, specific heat $0.84 \mathrm{~kJ} /(\mathrm{kg} \cdot \mathrm{K})$ ). In order to avoid destruction of the tunnel, iron plates (density $7850 \mathrm{~kg} / \mathrm{m}^{3}$, heat conductivity $45.8 \mathrm{~W} /(\mathrm{m} \cdot \mathrm{K})$, specific heat $\left.0.46 \mathrm{~kJ} /(\mathrm{kg} \cdot \mathrm{K})\right)$ replace the fireproof glass of the ceiling and the floor near the location of the fire.

In 7 tests, longitudinal ventilation (with velocity $0.8 \mathrm{~m} / \mathrm{s}$, see below) was established by an electrically driven axial fan at the entrance of the tunnel. The test protocol was such that the ventilation system was activated at $\mathrm{t}=20 \mathrm{~s}$ after ignition of the fuel. In order to smoothen the air flow from the fan, a net with small grid size $(1 \mathrm{~cm} \times 1 \mathrm{~cm})$ was installed at the outlet of axial fan.

\subsection{Water system}

The water system with 13 nozzles in 5 rows $(\mathrm{A}-\mathrm{E})$ is presented in Figure 2. The left hand side shows a sketch, while the right hand side shows a picture. Nozzles in the same row are connected by a pipe with a valve to control opening or closure of the nozzle rows. Through the use of these valves, different nozzle arrangements can be considered. When 4 nozzles are activated (' $2 \times 2$ ' in Table 2), rows A and C are open. With 5 nozzles ('2+3' in Table 2), rows D and E are open, while rows B and D are used in the tests with 6 nozzles (' $2 \times 3$ ' in Table 2). All nozzles have been installed $25 \mathrm{~mm}$ below the ceiling and the distance between two neighboring rows is $0.3 \mathrm{~m}$, except for row $\mathrm{E}$, which is $0.6 \mathrm{~m}$ from row $\mathrm{D}$. A water 
pump supplies the water for all the nozzles. The maximum total water flow rate is $3.5 \mathrm{~m}^{3} / \mathrm{h}$ and the maximum pressure is $0.65 \mathrm{MPa}$. Three pressure gauges have been installed in the water supply pipe adjacent to the water pump and nozzles, respectively. Only the data on pressure gauges near the nozzles are used to control the water supply rate to the nozzles. Two levels of pressure have been applied in the tests, namely $0.3 \mathrm{MPa}$ and $0.5 \mathrm{MPa}$. In order to assure that the flow rate for each nozzle row is the same, the valves have been adjusted before the tests, keeping the pressure at constant level. The test protocol was such that the water supply is activated at $t=20 \mathrm{~s}$ after ignition of the fuel in the absence of longitudinal ventilation. In case of longitudinal ventilation, the water supply is activated at $\mathrm{t}=40 \mathrm{~s}$ after fuel ignition (i.e., $20 \mathrm{~s}$ after activation of the longitudinal ventilation system).

\subsection{Instrumentation}

Temperatures have been measured with unshielded K-type thermocouples. The accuracy of each thermocouple is $+/-0.1^{\circ} \mathrm{C}$. Their location is shown in Figures 1 and 3: thermocouple trees were installed every $1.5 \mathrm{~m}$ along the length of the tunnel. Each tree has been placed in the vertical symmetry plane of the tunnel and contains three thermocouples, at heights $0.04 \mathrm{~m}, 0.2 \mathrm{~m}$ and $0.36 \mathrm{~m}$ above the floor. All thermocouples were connected to a data logging system, recording the temperature every 5 seconds.

Figure 1 also shows a 'weighing platform', used to measure the evolution in time of the fuel mass (from which the mass loss rate or burning rate can be derived, as explained in the next section). The accuracy of the mass measurement is $+/-0.1 \mathrm{~g}$. The data has been recorded by a video camera.

\subsection{The fire load}

Methanol has been used as fuel in the experiments. An iron box ( $25 \mathrm{~cm}$ long, $20 \mathrm{~cm}$ wide and $6 \mathrm{~cm}$ high) was designed to contain the methanol. For each test, $250 \mathrm{ml}$ methanol has been used. At first, the fuel 
mass loss rate was measured in different ventilation conditions, with and without activation of the water system. The mass loss rate is calculated as:

$$
\dot{m}_{\iota}=\frac{m_{i}-m_{i+1}}{t_{i+1}-t_{i}}
$$

where the time interval $\left(t_{i+1}-t_{i}\right)$ has been chosen as 5 seconds, corresponding to the temperature recording time. $m_{i}$ and $m_{i+1}$ are the corresponding fuel mass at times $t_{i}$ and $t_{i+1}$. Figure 4 shows the evolution in time of the instantaneous mass loss rate. In the curve 'no ventilation', neither the ventilation system, nor the water system was activated. The solid line refers to the situation where the ventilation system operates such that a longitudinal velocity of $0.8 \mathrm{~m} / \mathrm{s}$ is created. The water system still does not operate. The dashed line ('water system, no ventilation') refers to conditions without longitudinal ventilation, but with activation of the water system (rows D and E activated with water pressure $0.5 \mathrm{MPa}$ ). Clearly, neither the longitudinal ventilation, nor the activation of the water system have a strong impact on the mass loss rate. This illustrates that the fire dynamics in the tests is not affected by the activation of the systems.

From the data during the steady state phase (taken from 100s to 200s), the average steady burning rate was calculated to be $0.018 \mathrm{~kg} / \mathrm{m}^{2} \cdot \mathrm{s}$ in the absence of ventilation and $0.017 \mathrm{~kg} / \mathrm{m}^{2} \cdot \mathrm{s}$ with ventilation (with $0.8 \mathrm{~m} / \mathrm{s}$ ventilation velocity). This is in good agreement with values reported in the literature

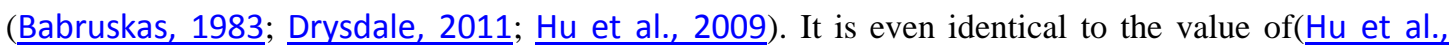
2009), where the settings were similar to the present study (a $20 \mathrm{~cm} \times 20 \mathrm{~cm}$ tray was used in ( $\mathrm{Hu}$ et al.) with $0.8 \mathrm{~m} / \mathrm{s}$ longitudinal velocity.

The corresponding heat release rate is calculated as:

$$
\text { HRR }=\text { mass loss rate } \times \text { heat of combustion } \times \text { combustion efficiency }
$$

Using a heat of combustion of $19.83 \mathrm{~kJ} / \mathrm{g}$ (Drysdale, 2011) and a combustion efficiency of 0.9 , this 
leads to a $H R R=16 \mathrm{~kW}$ (without ventilation) or $15.2 \mathrm{~kW}$ (with $0.8 \mathrm{~m} / \mathrm{s}$ ventilation velocity) .

\subsection{Nozzle testing}

The nozzles create fine water droplets within a cone-shaped region. The nozzle orifice diameter is $2 \mathrm{~mm}$.

In order to measure the spray angle, pictures were taken with a camera, placed behind the nozzle.

Meanwhile a measuring cylinder was used to measure the water flow rate (see Table 1). The droplet diameter distribution was determined by a glass sheet, covered with vaseline, positioned $1 \mathrm{~m}$ below the nozzle during 1s. Then the glass was investigated in a microscope (Olympus CX31), with an accuracy of $+/-0.01 \mathrm{~mm}$. The diffusion coefficient is 0.84 .100 droplets were randomly selected and measured to determine the diameter distribution.

Figure 6 reveals that there is reasonable agreement of the measured droplet diameter distribution with the Rosin-Rammler distribution function(Svarovsky, 2000), assuming that there is an exponential relationship between the droplet diameter $\mathrm{d}$, and the mass fraction $\left(\mathrm{Y}_{\mathrm{d}}\right)$ of droplets with diameter larger than d:

$$
\mathrm{Y}_{\mathrm{d}}=\mathrm{e}^{-(\mathrm{d} / \overline{\mathrm{d}})^{\mathrm{n}}}
$$

In Eq. (3), $\bar{d}$ refers to the Mean Diameter and $n$ is the Spread Parameter. The values are provided in

Table 1. As expected, smaller droplets are obtained with the higher water pressure.

Table 1. Characteristic values for the nozzle sprays

\begin{tabular}{|c|c|c|c|c|}
\hline $\begin{array}{c}\text { Water pressure } \\
(\mathrm{MPa})\end{array}$ & $\begin{array}{c}\text { Spray angle } \\
\rho\end{array}$ & $\begin{array}{c}\text { Water flow rate } \\
\text { for a nozzle }(\mathrm{l} / \mathrm{min})\end{array}$ & $\begin{array}{c}\text { Mean Diameter } \\
(\mu \mathrm{m})\end{array}$ & $\begin{array}{c}\text { Spread } \\
\text { Parameter }\end{array}$ \\
\hline 0.5 & 74 & 1.94 & 368 & 3.5 \\
\hline 0.3 & 66 & 1.59 & 460 & 4.8 \\
\hline
\end{tabular}

2.6 Summary of test settings

Table 2 summarizes the settings of the 14 fire tests.

Table 2. Overview of the settings in the different fire tests. ' $2 \times 2$ : rows $A$ and $C$ are open (Fig. 2 ); ' $2+3$ ': rows D and E are open; 


\begin{tabular}{|c|c|c|c|}
\hline Test NO. & Ventilation velocity $(\mathrm{m} / \mathrm{s})$ & Nozzle arrangement & Water Pressure $(\mathrm{MPa})$ \\
\hline 1 & 0 & $/$ & $/$ \\
\hline 2 & 0.8 & $2 \times 2$ & 0.5 \\
\hline 3 & 0 & $2 \times 2$ & 0.5 \\
\hline 4 & 0.8 & $2 \times 3$ & 0.5 \\
\hline 5 & 0 & $2 \times 3$ & 0.5 \\
\hline 6 & 0.8 & $2+3$ & 0.5 \\
\hline 7 & 0 & $2+3$ & 0.5 \\
\hline 8 & 0.8 & $2 \times 2$ & 0.3 \\
\hline 9 & 0 & $2 \times 2$ & 0.3 \\
\hline 10 & 0.8 & $2 \times 3$ & 0.3 \\
\hline 11 & 0 & $2 \times 3$ & 0.3 \\
\hline 12 & 0.8 & $2+3$ & 0.3 \\
\hline 13 & 0 & $2+3$ & 0.3 \\
\hline 14 & 0.8 & & \\
\hline
\end{tabular}

\subsection{Discussion: scaling}

The set-up is a reduced-scale tunnel, scaling down from a real tunnel ( $4 \mathrm{~m}$ high and $12 \mathrm{~m}$ wide). The scaling factor for these geometrical length scales is thus 10. The exact length of the tunnel is of lesser importance, since a section of the tunnel is addressed.

The scaling theory(Heskestad, 2002) relies upon conservation of the Froude number $(\mathrm{Fr}=\mathrm{v} / \sqrt{g L})$, assuming unchanged temperatures in the scaling process. The resulting scaling laws, including the water system, have been reported in the literature ${ }^{11}$ and are summarized in Table 3.

Scaling up from the small-scale experiments, a HRR of $16 \mathrm{~kW}$ in the reduced-scale tunnel then corresponds to 5MW, which roughly corresponds to the HRR of a single burning car(Merci and Shipp, $\underline{2013})$. The ventilation velocity $(0.8 \mathrm{~m} / \mathrm{s})$ corresponds to $2.5 \mathrm{~m} / \mathrm{s}$, which is in the order of magnitude of the critical ventilation velocity for the configuration considered(Tilley et al., 2011). This justifies the choice of $0.8 \mathrm{~m} / \mathrm{s}$ as ventilation velocity in the reduced-scale tunnel. The water flow rates (see Table 1) would scale up to 610 1/min, resp. 500 1/min, assuming nozzles with orifice diameter equal to $2 \mathrm{~cm}$. The 
mean droplet diameters then scale up to $1075 \mu \mathrm{m}$, resp. $1230 \mu \mathrm{m}$, so the system is not truly a water mist system anymore. Yet, this is not essential for the paper at hand.

Table 3. Summary of scaling laws ${ }^{11}$.

\begin{tabular}{|c|c|}
\hline Type of unit & Scaling model \\
\hline Heat Release Rate (HRR) (kW) & $\dot{Q} \propto L^{5 / 2}$ \\
\hline Ventilation velocity (m/s) & $V \propto L^{1 / 2}$ \\
\hline Water flow rate (I/min) & $\dot{q_{W}} \propto L^{5 / 2}$ \\
\hline Water droplet diameter $(\mu \mathrm{m})$ & $d_{W} \propto L^{1 / 2}$ \\
\hline
\end{tabular}

\section{Test Results}

In this section, a selection of processed experimental data is discussed. Time $t=0$ is defined as the moment of fuel ignition. In the tests with even number in Table 2, the longitudinal ventilation system is activated at $\mathrm{t}=20 \mathrm{~s}$ and, except for Test 2 (where the water system does not operate), the water supply is activated at $\mathrm{t}=40 \mathrm{~s}$. In the tests with odd number in Table 2, there is no longitudinal ventilation and, except for Test 1 , the water supply is activated at $\mathrm{t}=20 \mathrm{~s}$.

Smoke blocking is determined from temperature measurements. The basic assumption is that the presence of smoke is directly correlated to an increase in temperature, since the thermal and mass diffusivity are almost identical.

First, results are discussed without and with longitudinal ventilation. After that, the impact of the nozzle arrangement and the water pressure is reported.

\subsection{Smoke blocking - no longitudinal ventilation}

To discuss the effectiveness of smoke blocking in a naturally ventilated tunnel, tests 1 and 3 have been selected from Table 2. In test 3, no smoke was observed visually downstream of the water system (Fig. 7, showing the situation 60 s after water system discharged in the tunnel). This is confirmed in the 
temperature data, shown in Figs. 8 (Test 1) and 9 (Test 3). These figures show temperature profiles in the tunnel at different times. The red rectangle shows the position of the fire source, while the blue rectangle represents the presence of the water system. In test 1, temperatures decrease progressively from fire location (position 4) to exit of tunnel (position 12). In test 3, with the activation of water system, temperatures in tunnel decrease compared to Test 1 , especially at positions near the water system, due to the cooling effect of the water.

Fig. 10 and Fig. 11 show the temperature data in a different manner, namely as evolutions in time at positions upstream (position 7) and downstream (position 10) of the water system. Figure 11 (Test 3) clearly shows that smoke cannot pass the water system: the temperatures downstream of the water system drop to almost ambient temperature.

The temperature rise observed at around $40 \mathrm{~s}$ in test 3 at ceiling height at position 10 (Fig. 11) shows that smoke had already passed the water system before it was activated. Interestingly, Fig. 10 reveals the cooling effect of the water droplets near position 7: the temperatures in test 3 near the ceiling are lower than the ones for test 1 . Figure 10 also illustrates the destruction of the smoke stratification: whereas the temperatures at mid-height are relatively low without activation of the water system, because the thermocouples are not within the hot smoke layer underneath the ceiling, they are higher upon activation of the water system. Indeed, the smoke is blocked and moves downward due to the water system. As it flows back towards the fire source, there is strong mixing in the region in between the fire source and the water system and the smoke fills that entire region.

In short, it can be concluded that, in the absence of longitudinal ventilation, smoke is blocked by the water system.

\subsection{Smoke blocking - with longitudinal ventilation}


Tests 2 and 4 have been selected from Table 2 for the analysis with longitudinal ventilation. Fig. 12 illustrates the smoke in the tunnel with longitudinal ventilation, i.e., the water system does not block the smoke.

Fig.13 and 14 show the evolution of the temperatures at the thermocouples closest to the ceiling. In these two tests, the ventilation system is active, so the temperatures are lower than the ones without ventilation system (Figs. 8 and 9). However, as the fresh air blows smoke towards the exit of tunnel, the smoke blocking effect of the water system is no longer in place. The cooling effect of the water upstream is less significant than in the absence of longitudinal ventilation, as expected. Indeed, the water droplets are blown backward and the cooling effect by the longitudinal ventilation is already significant. Downstream of the water system, the reduction in temperature remains significant. Temperatures become even lower than ambient, due to the cool water.

Figures 15, 16 and 17 show temperature evolutions upstream and downstream of the water system. As the hot smoke flows towards the exit of tunnel, its temperature decreases. This leads to destratification: while there is still clear stratification at positions 5 and 7 (Figs. 15 and 16), the temperature at mid-height upstream is almost identical to the temperature at the ceiling at position 11 (Fig. 17). Obviously, the discharge of water fortifies the destratification and the temperatures are lower due to the cooling effect by the water.

In summary: In contrast to the naturally ventilated tunnel, the smoke crosses the water system due to the imposed longitudinal ventilation. A cooling effect of the water is observed through reduced smoke temperatures.

\subsection{The effect of the nozzle arrangement - no longitudinal ventilation}

In this section smoke and temperature changes caused by different nozzle arrangements are discussed, 
comparing results of Tests 9, 11 and 13 from Table 2 . A different number of nozzles are activated $(2 \times 2$ in Test $9,2 \times 3$ in Test 11 and $2+3$ in Test 13). Thus, for a given water pressure level, the water flow rate through each nozzle being constant, the different nozzle arrangements reflect different total water flow rates.

Figs. 18 - 20 reveal small temperature differences upstream of the water system: without ventilation system, smoke is essentially blocked by the water system, regardless of the number of nozzles activated in the test. This was confirmed by visual observations and is also reflected in Figs. 21 and 22, showing temperature evolutions upstream of the water system. Differences between the different nozzle set-ups are small. Fig. 23 seems to indicate larger differences. These can be explained by the position of the nozzles (Fig. 2): in test 13, the nozzle rows (D and E) closest to the fire are activated, so more smoke has already passed the water system before it is activated, compared to tests 11 (rows B and D) and 9 (rows A and C). Once activated, the smoke is blocked by the water system and temperatures decrease to the same level for all nozzle configurations.

In conclusion, in the absence of longitudinal ventilation, smoke is blocked, regardless of the nozzle arrangement as tested. This implies that a water system with 4 nozzles (Test 9) can effectively block smoke for the configuration at hand and adding more nozzles does not have a strong impact on the smoke blocking effect.

\subsection{The effect of the nozzle arrangement - with longitudinal ventilation}

For this study, Tests 10, 12 and 14 are selected from Table 2. As expected, Figs. $24-29$ confirm that the effect of the nozzle arrangement is also small in the presence of longitudinal ventilation (i.e., the findings of the previous section prevail). The relatively large differences observed in Fig. 23 are not visible in Fig. 29: due to the longitudinal ventilation, the smoke reaches the thermocouples downstream 
of the water system more rapidly, so that similar amounts of smoke have already crossed the water system before its activation, regardless of the position of the water nozzle rows in the tests. Due to the high longitudinal ventilation velocity, the contact time between water mist and smoke is short, which limits the cooling effect by the water system. Differences in nozzle arrangements have only a small influence on the temperature downstream of the water system.

\subsection{The effect of water pressure - no longitudinal ventilation}

In this section, the effect of the water pressure is discussed, without longitudinal ventilation, comparing Tests 3 and 9 from Table 2 . Only the configuration with $2 \times 2$ nozzles is discussed, since similar findings hold for the other configurations. As expected, Figs. $30-32$ reveal that the cooling effect is stronger for higher water pressure. Indeed, lower temperatures are found in Test 3: the higher water pressure implies both a higher water flow rate and the production of smaller water droplets by the nozzles. Downstream of the water system, temperatures are similar, indicating that also the lower water pressure is sufficient to block the smoke in the tests at hand.

\subsection{The effect of water pressure - with longitudinal ventilation}

In this section, test 4 and test 10 are selected from Table 2 . With longitudinal ventilation of $0.8 \mathrm{~m} / \mathrm{s}$, smoke passes the water system, as explained above. Figs. 33 - 35 generally confirm the stronger cooling effect with higher water pressure, for the reasons stated in the previous section. Yet, the effect is much less pronounced than in the naturally ventilated tunnel, since the residence time of the smoke in the water system is shorter and the forced longitudinal ventilation already has a cooling effect on the smoke.

\section{Conclusion}

Experimental data have been discussed on the effect of smoke blocking and temperature reduction by a 
water system in a reduced-scale tunnel, with and without forced longitudinal ventilation. Experimental data concerns temperature fields, extracted from thermocouple trees at different longitudinal positions in the vertical center plane of the tunnel, with measurements at three heights per tree.

It has been illustrated that in the naturally ventilated tunnel, the installed water mist system effectively prevents smoke spreading. The water also has a strong cooling effect on the smoke in the tunnel. These observations were confirmed, regardless of the nozzle arrangement $(2 \times 2,2 \times 3$ or $2+3$ nozzles $)$ or the water pressure imposed (0.3MPa or $0.5 \mathrm{MPa})$.

With longitudinal ventilation in place, with velocity $0.8 \mathrm{~m} / \mathrm{s}$ in the reduced-scale tunnel, the smoke is no longer blocked. The smoke is still cooled down by the water, but the effect is smaller than for the naturally ventilated tunnel, because residence times are shorter and the forced ventilation also already has a cooling effect on the smoke.

Also with longitudinal ventilation in place, the impact of the nozzle arrangement is small, for a given level of water pressure.

For all configurations, a higher water pressure in the water system leads to stronger cooling effects, due to the production of more and smaller water droplets. Yet, the effect is much less pronounced when longitudinal ventilation is in place, since the residence time of the smoke in the water system is shorter than for a naturally ventilated tunnel and the forced longitudinal ventilation already has a cooling effect on the smoke.

\section{Acknowledgements}

This research has been funded by China Scholarship Council, NO.201306270111 (China).

Dr. Tarek Beji is a Postdoctoral Fellow of the Fund for Scientific Research-Flanders (Belgium).

\section{Reference}


Amano, R., Izushi, Y., Kurioka, H., 2005. Water Screen Fire Disaster Prevention System in Underground Space. 消防研究所報告, 243-249.

Babruskas, V., 1983. Estimating Large Pool Fire Burning Rates. Fire Technology 19, 251-261.

Blanchard, E., Boulet, P., Fromy, P., Desanghere, S., Carlotti, P., Vantelon, J.P., Garo, J.P., 2014. Experimental and Numerical Study of the Interaction Between Water Mist and Fire in an Intermediate Test Tunnel. Fire Technology 50, 565-587.

Carvel, R.B., A., 2005. The Handbook of Tunnel Fire Safety. Thomas Telford.

Chen, L., Zhu, W., Cai, X., Pan, L., Liao, G., 2009. Experimental study of water mist fire suppression in tunnels under longitudinal ventilation. Building and Environment 44, 446-455.

Drysdale, D., 2011. An Introduction to Fire Dynamics. Wiley.

Grant, G.B., J. Drysdale, D., 2000. Fire suppression by water sprays. Progress in Energy and Combustion Science 26, 79-130.

Hart, R.A., 2006. NUMERICAL MODELLING OF TUNNEL FIRES AND WATER MIST SUPPRESSION.

Heskestad, G., 2002. Scaling the interaction of water sprays and flames. Fire Safety Journal 37, 535-548.

Hu, L.H., Liu, S., Peng, W., Huo, R., 2009. Experimental study on burning rates of square/rectangular gasoline and methanol pool fires under longitudinal air flow in a wind tunnel. Journal of Hazardous Materials 169, 972-979.

Ingason, H., 2008. Model scale tunnel tests with water spray. Fire Safety Journal 43, 512-528.

Jenft, A., Collin, A., Boulet, P., Pianet, G., Breton, A., Muller, A., 2014. Experimental and numerical study of pool fire suppression using water mist. Fire Safety Journal 67, 1-12.

Kim, S.C., Ryou, H.S., 2003. An experimental and numerical study on fire suppression using a water mist in an enclosure. Building and Environment 38, 1309-1316.

Li, Q., Zhang, P., Guo, S., Pan, R., Qin, J., Liao, G., 2013. Experimental Study on Suppression of $\mathrm{n}$-Heptane Pool Fire with Water Mist under Longitudinal Ventilation in Long and Narrow Spaces. Procedia Engineering 62, 946-953.

Merci, B., Shipp, M., 2013. Smoke and heat control for fires in large car parks: Lessons learnt from research? Fire Safety Journal 57, 3-10.

Nmira, F., Consalvi, J.L., Kaiss, A., Fernandez-Pello, A.C., Porterie, B., 2009. A numerical study of water mist mitigation of tunnel fires. Fire Safety Journal 44, 198-211.

Prasad, K., Patnaik, G., Kailasanath, K., 2002. A numerical study of water-mist suppression of large scale compartment fires. Fire Safety Journal 37, 569-589.

Roberts, B.O., 1993. Fire Suppression and Life without Halon, in: website, W.A.f.A.C.W. (Ed.).

Svarovsky, L., 2000. Solid-Liquid Separation. Elsevier Science.

Tilley, N., Rauwoens, P., Merci, B., 2011. Verification of the accuracy of CFD simulations in small-scale tunnel and atrium fire configurations. Fire Safety Journal 46, 186-193.

W.K. Chow, E.Y.L.M., Mabel K.K. Ip, 2011. Recent Experimental Studies on Blocking Heat and Smoke by a Water Curtain. International Journal on Engineering Performance-Based Fire Codes 10, 89-95.

Yang, P., Liu, T., Qin, X., 2010. Experimental and numerical study on water mist suppression system on room fire. Building and Environment 45, 2309-2316. 


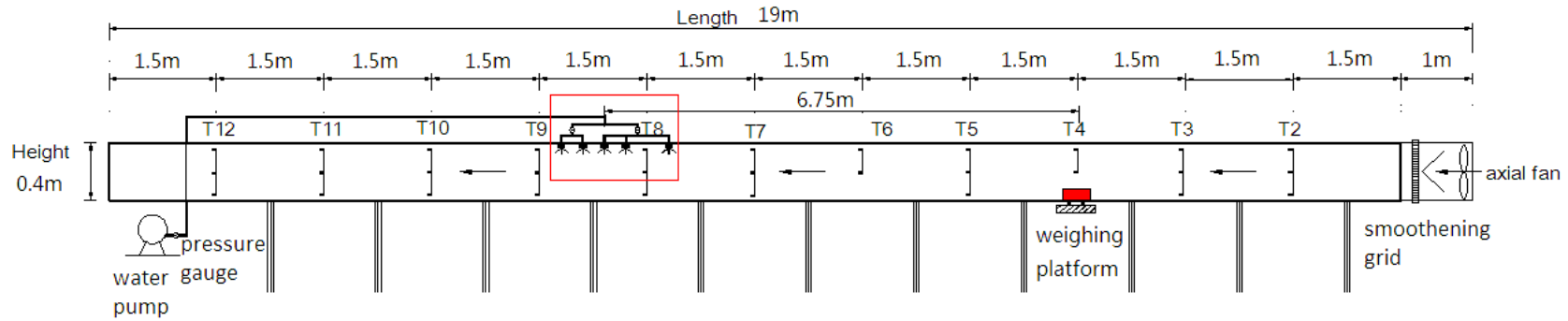

Figure 1. Sketch of the reduced-scale tunnel (side view: vertical section in the mid-plane).
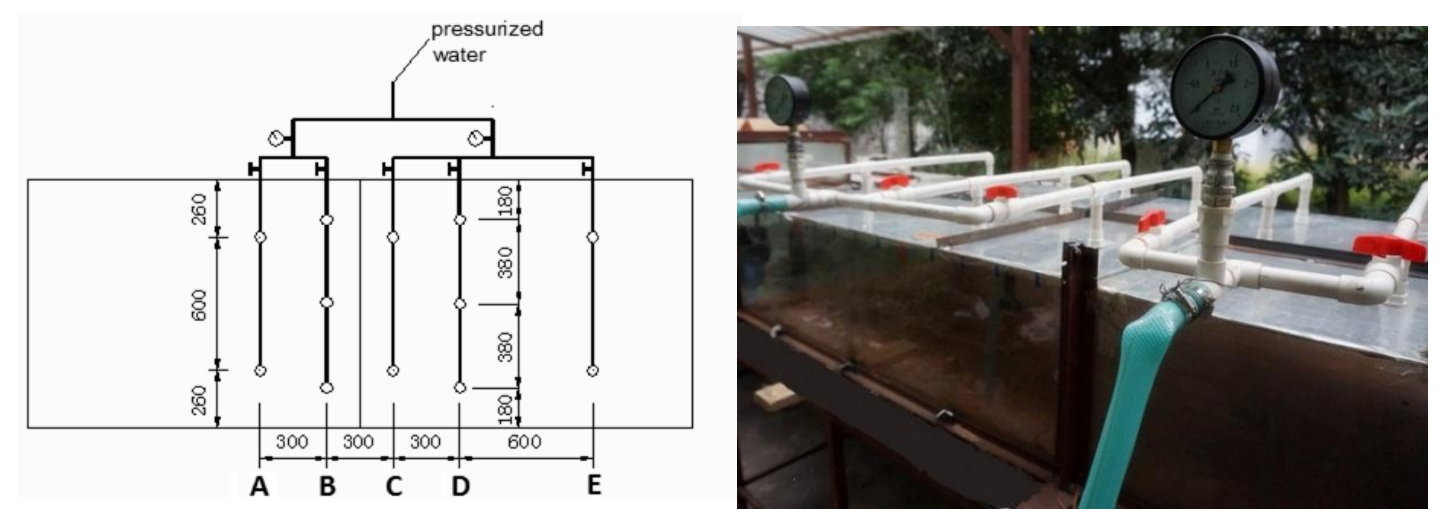

Figure 2. A bird-eye view sketch (left) and a picture (right) of the nozzle system lay-out. 

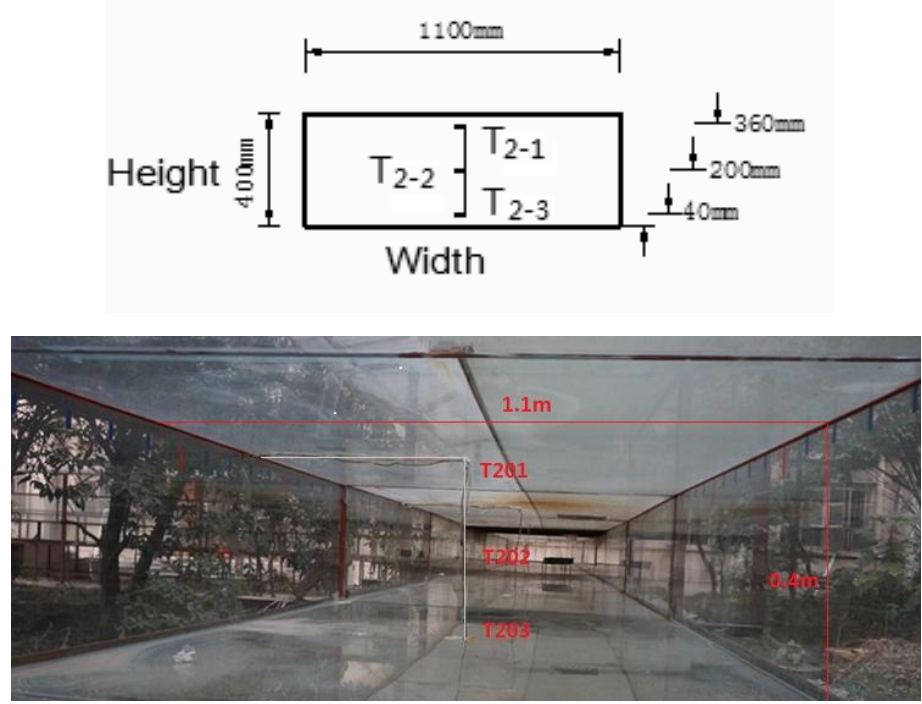

Figure 3. Sketch (top) and picture (bottom) of the thermocouple tree lay-out (cross section view).

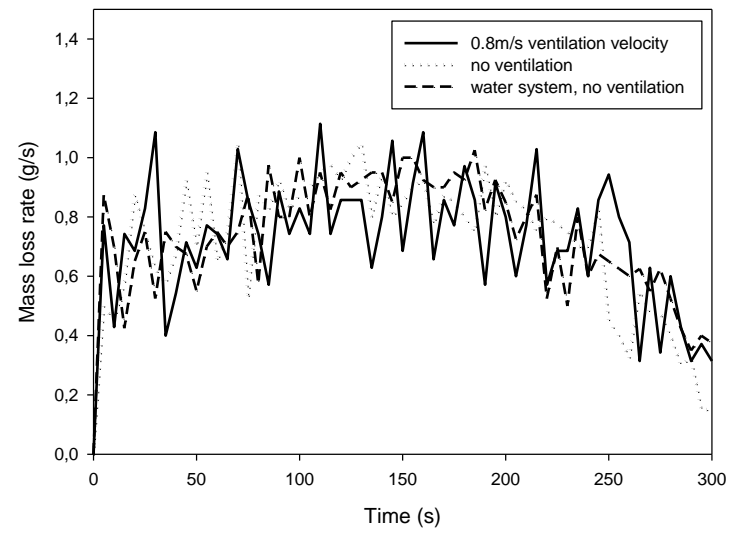

Figure 4. Evolution in time of the instantaneous mass loss rate. 'no ventilation': neither the ventilation system, nor the water system was activated; ' $0.8 \mathrm{~m} / \mathrm{s}$ ventilation velocity': Iongitudinal ventilation (with velocity $0.8 \mathrm{~m} / \mathrm{s}$ ), water system not activated; 'water system, no ventilation': no longitudinal ventilation, rows D and E activated with water pressure 0.5MPa. 


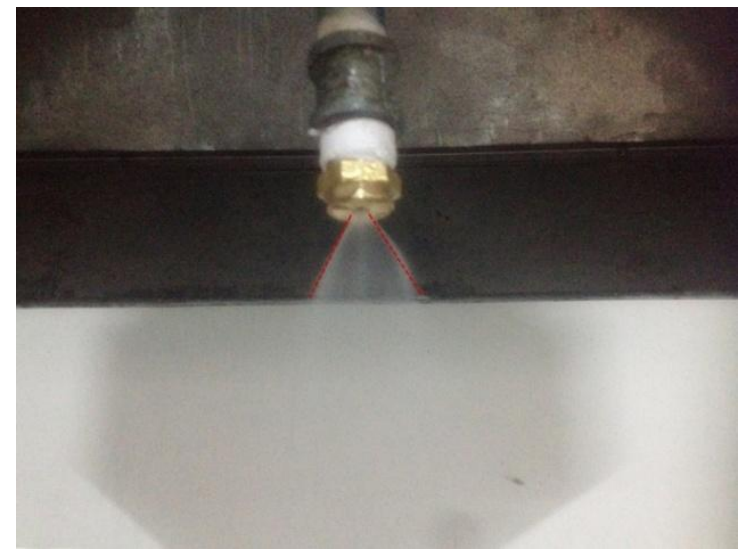

Figure 5. Illustration of the determination of the spray angle.
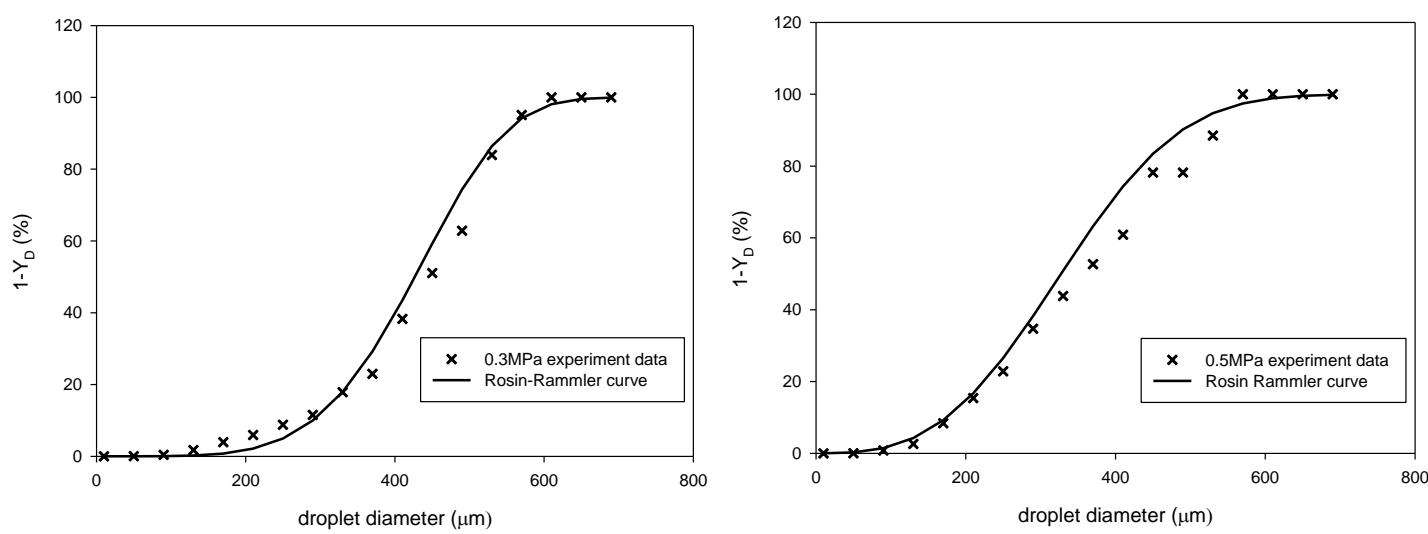

Figure 6. Measured droplet distribution compared to Rosin-Rammler curve fits for different water pressures. 


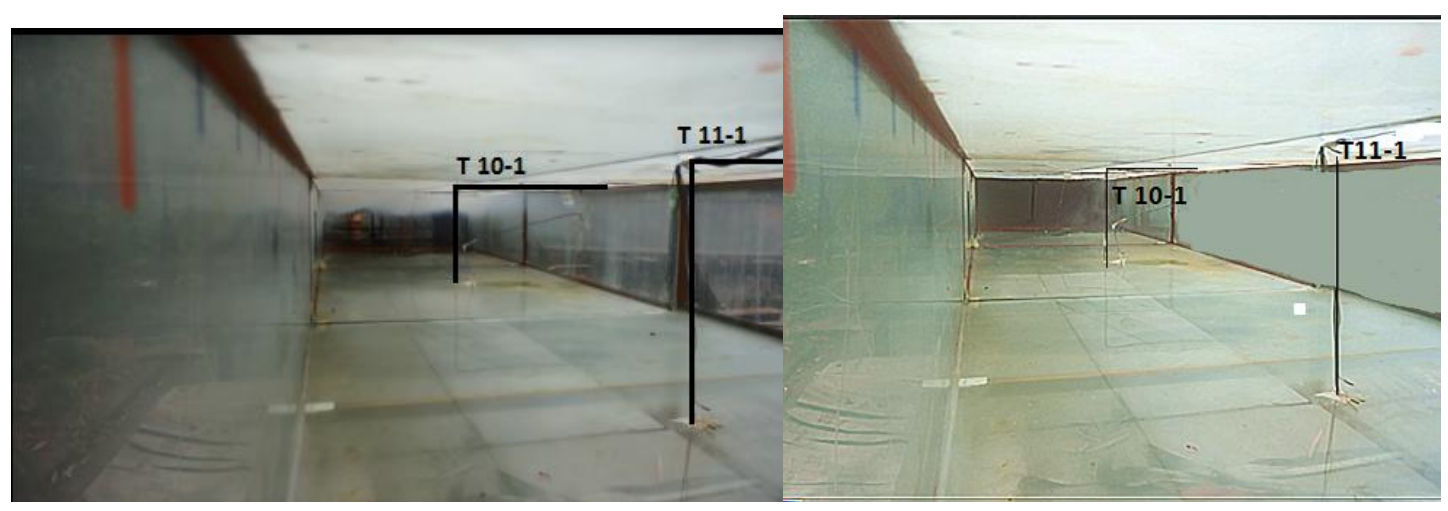

Figure 7. Picture at 20s after ignition (left) and 60s (right) after water system discharged

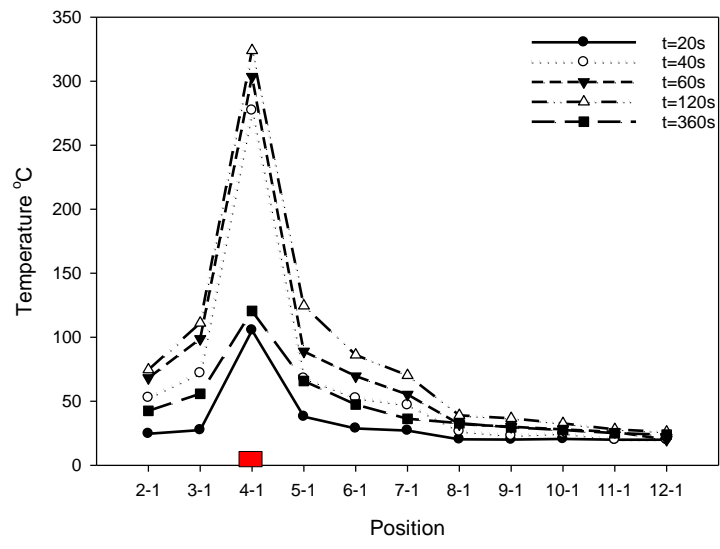

Figure 8. Temperature profile in tunnel (Test 1)

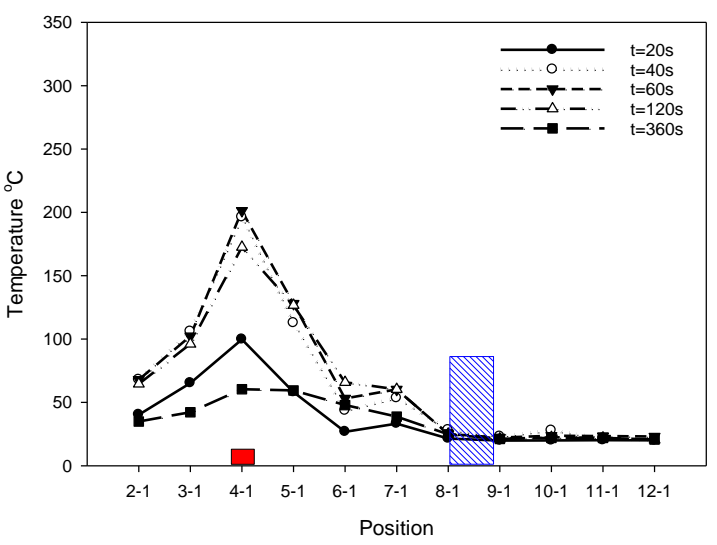

Figure 9. Temperature profile in tunnel (Test 3 ) 


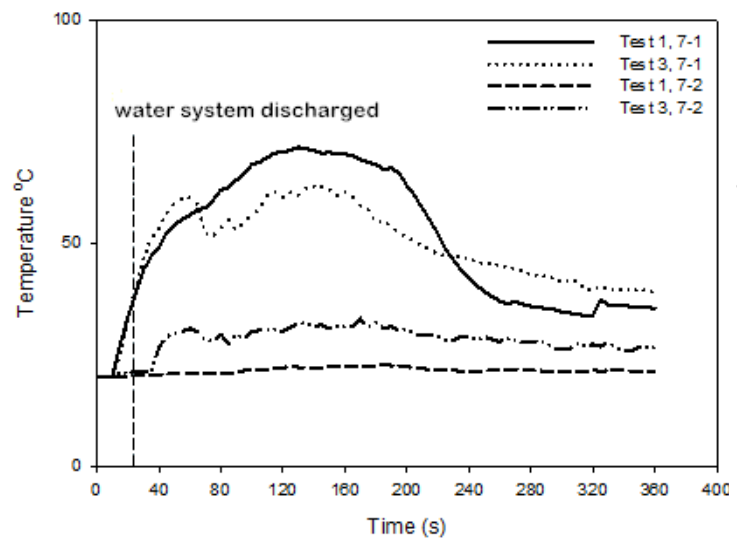

Figure 10. Temperature evolution at position 7
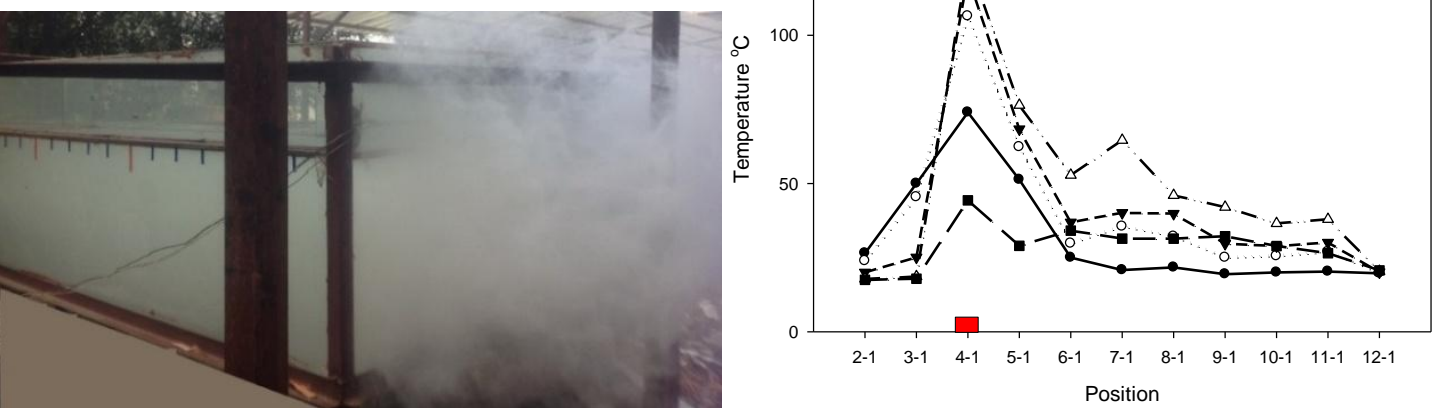

Figure 12. Smoke at exit of tunnel (60s after water system discharged) Figure 13. Temperature profile in tunnel （Test 2 ) 


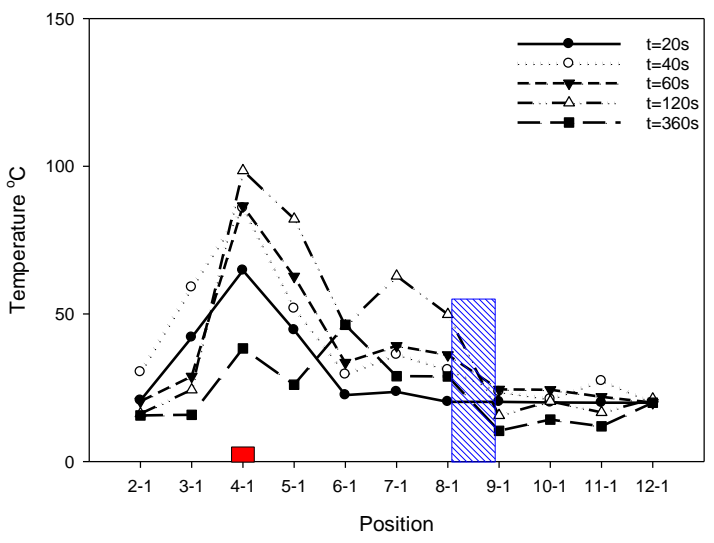

Figure 14. Temperature profile in tunnel (Test 4)

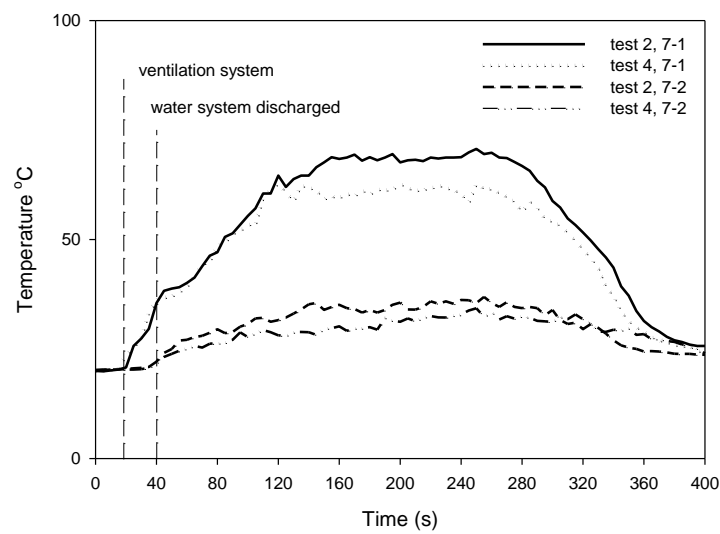

Figure 16. Temperature evolution at positions 7

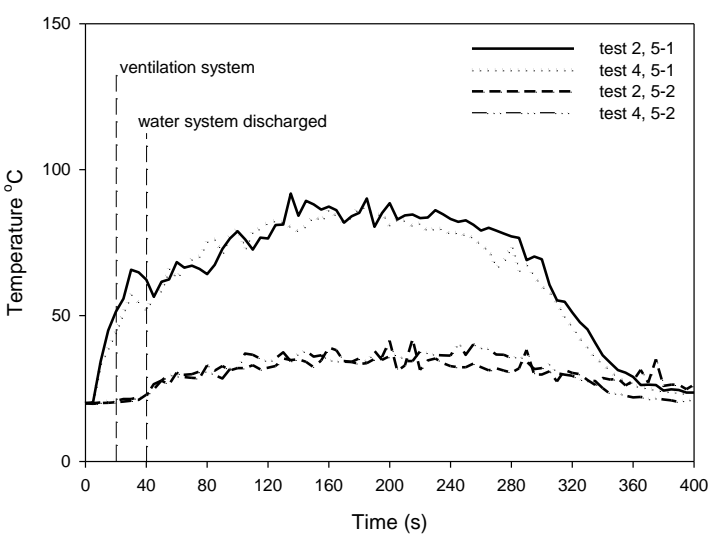

Figure 15. Temperature evolution at positions 5

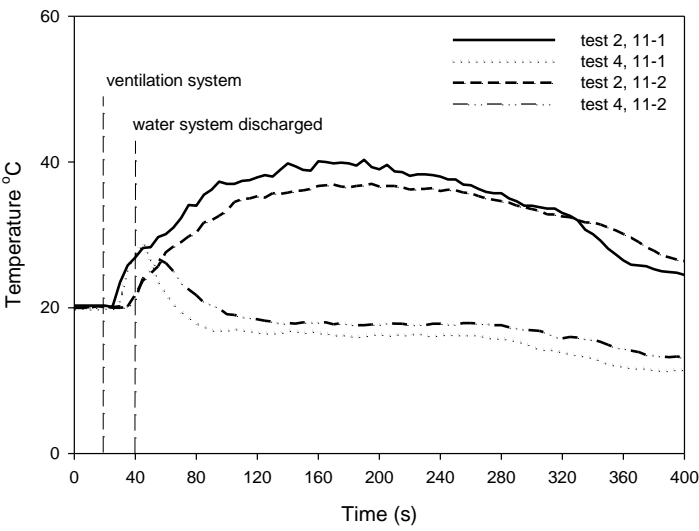

Figure 17. Temperature evolution at positions 11 

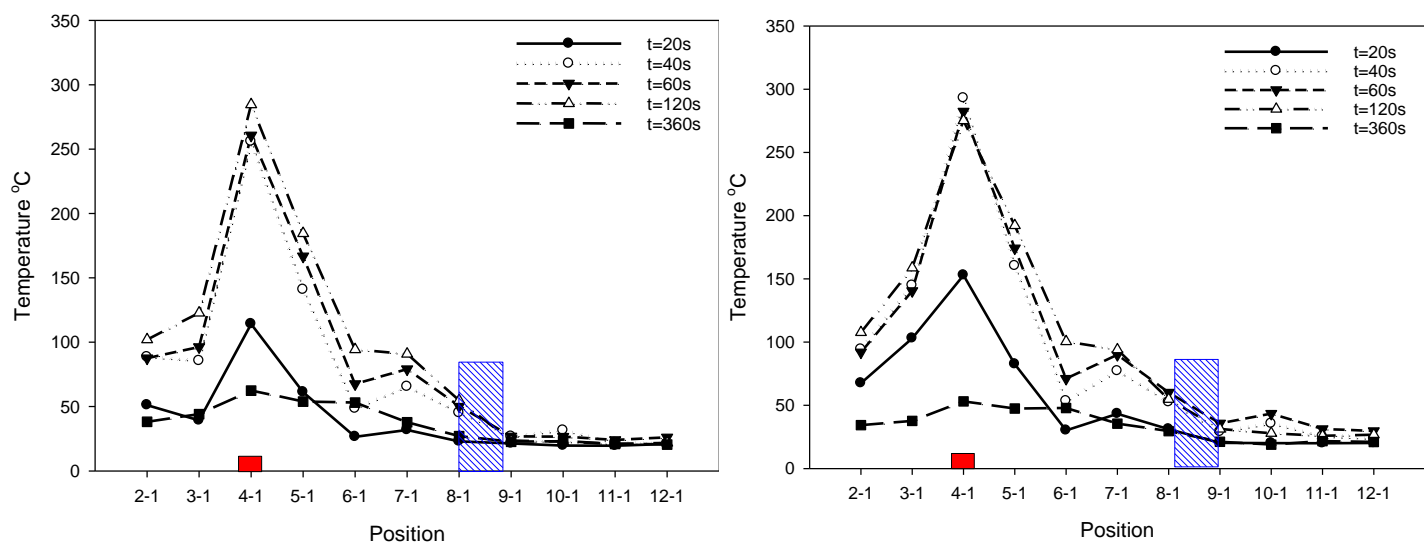

Figure 18. Temperature profile in tunnel (Test 9)

Figure 19. Temperature profile in tunnel (Test 11)
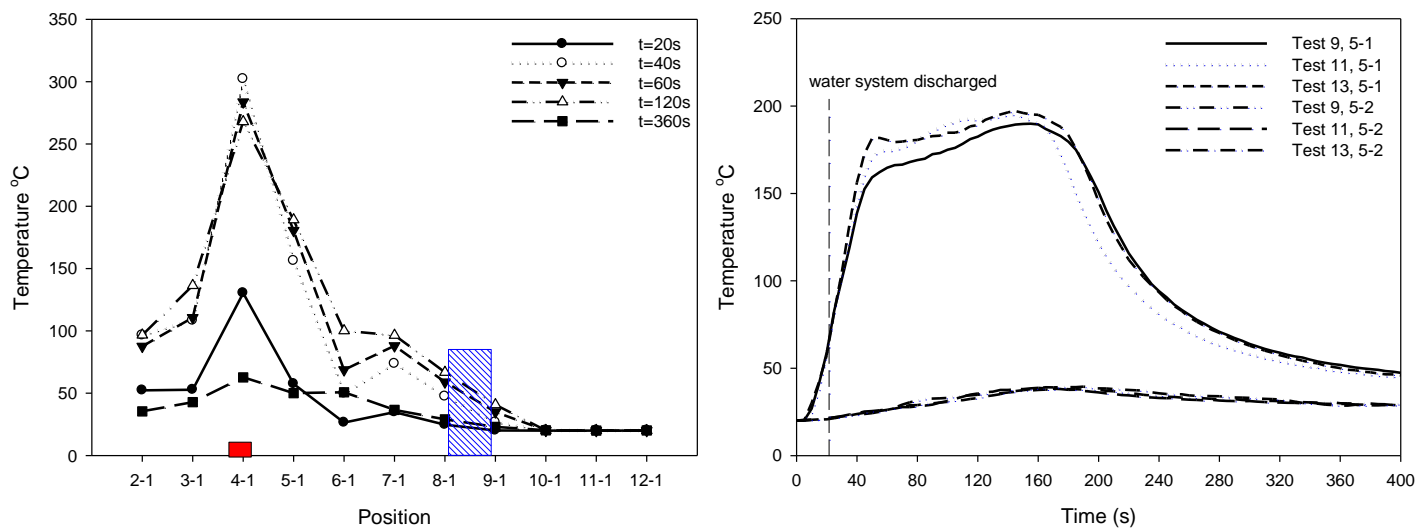

Figure 20. Temperature profile in tunnel (Test 13)

Figure 21. Temperature evolution at positions 5 


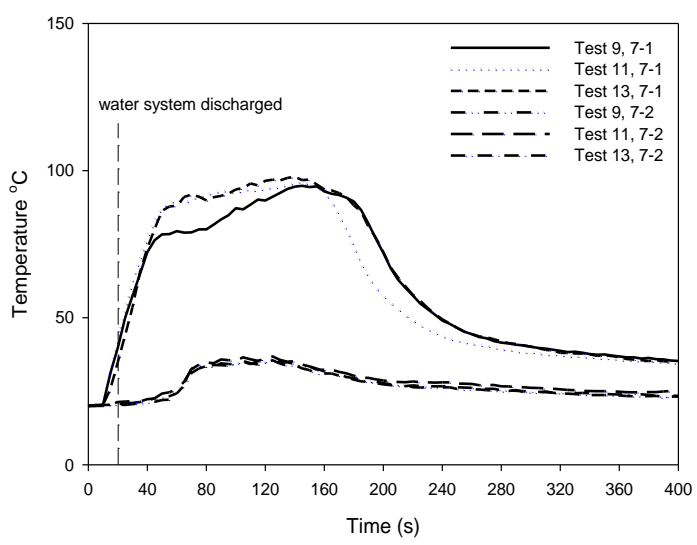

Figure 22. Temperature evolution at positions 7

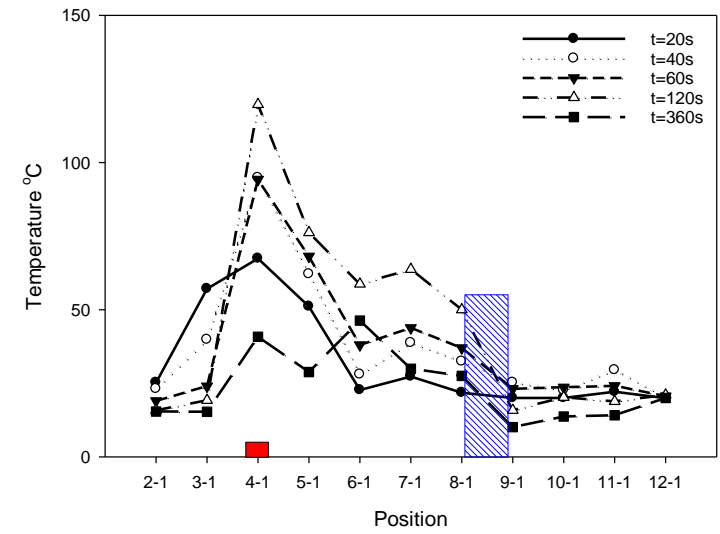

Figure 24. Temperature profile in tunnel (Test 10)

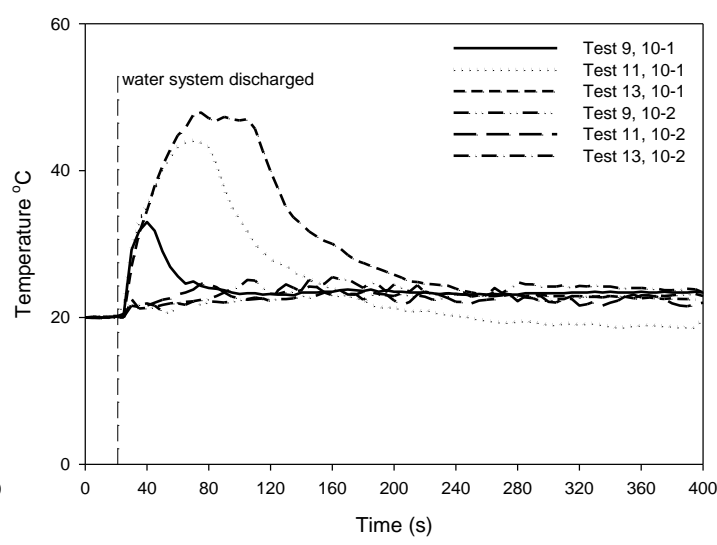

Figure 23. Temperature evolution at positions 10

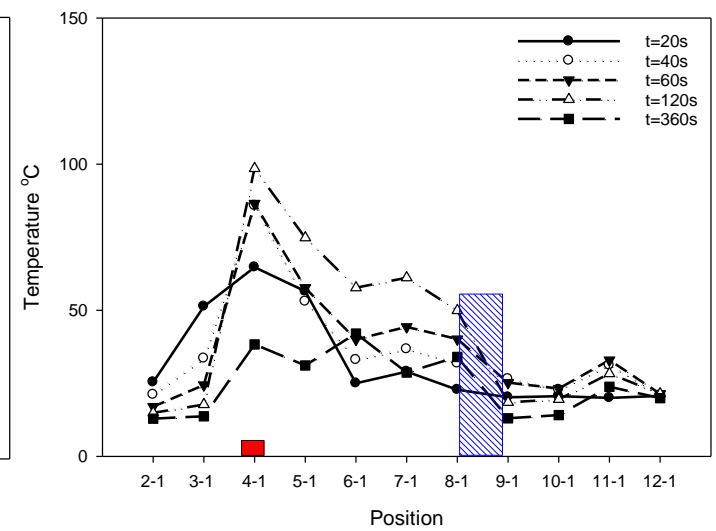

Figure 25. Temperature profile in tunnel (Test 12) 


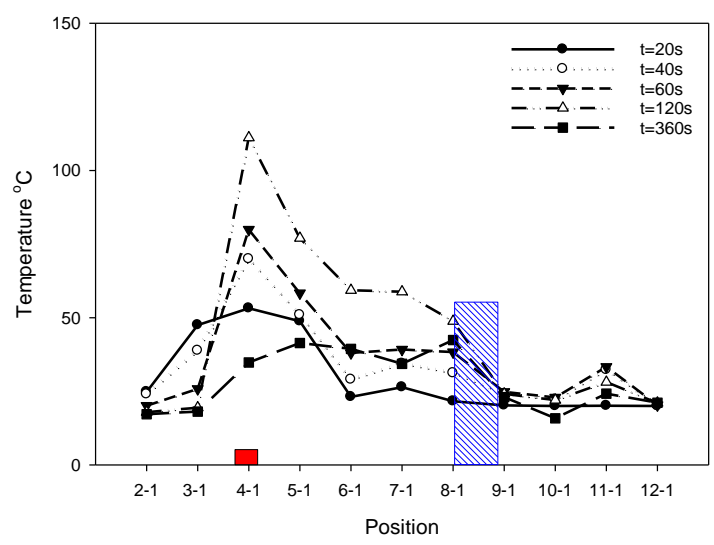

Figure 26. Temperature profile in tunnel (Test 14)

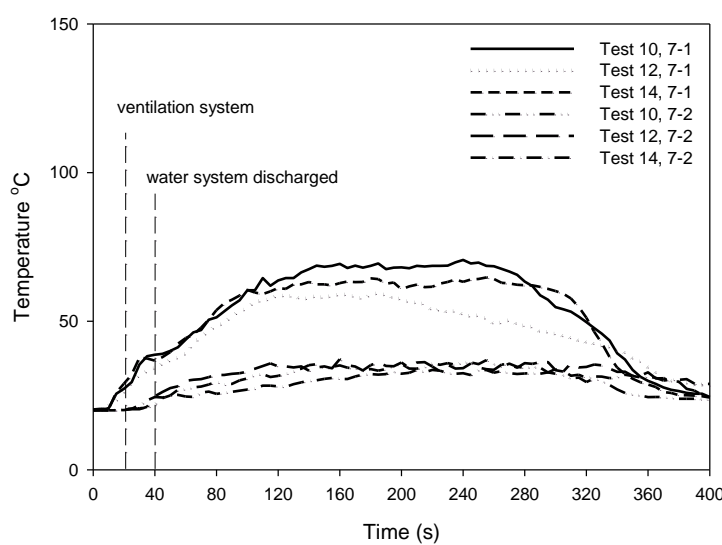

Figure 28. Temperature evolution at positions 7

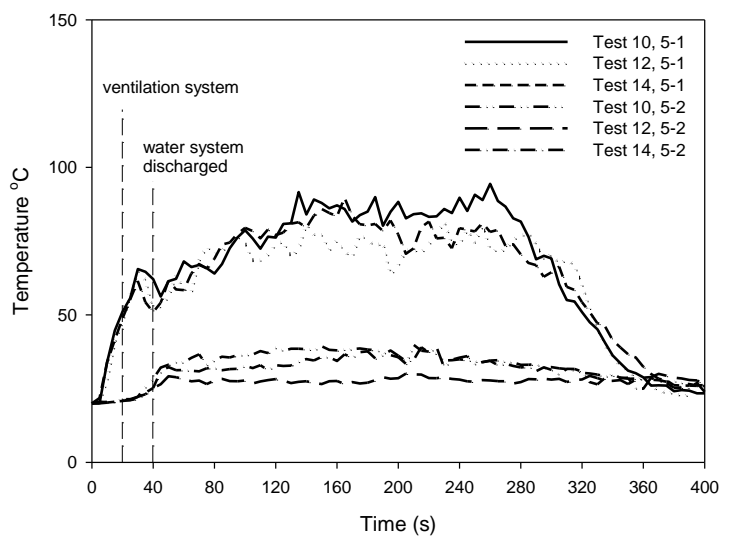

Figure 27. Temperature evolution at positions 5

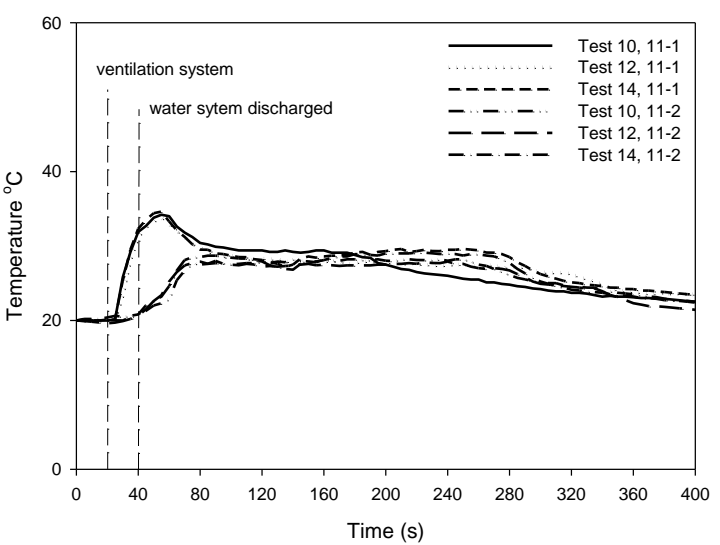

Figure 29. Temperature evolution at positions 11 


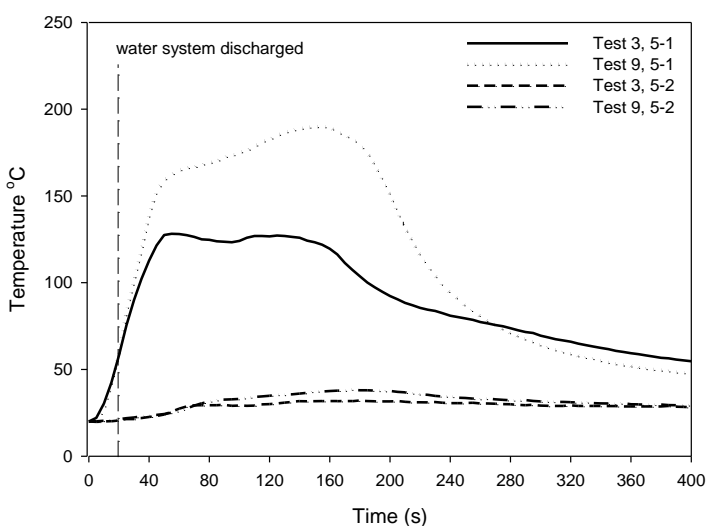

Figure 30. Temperature evolution at positions 5

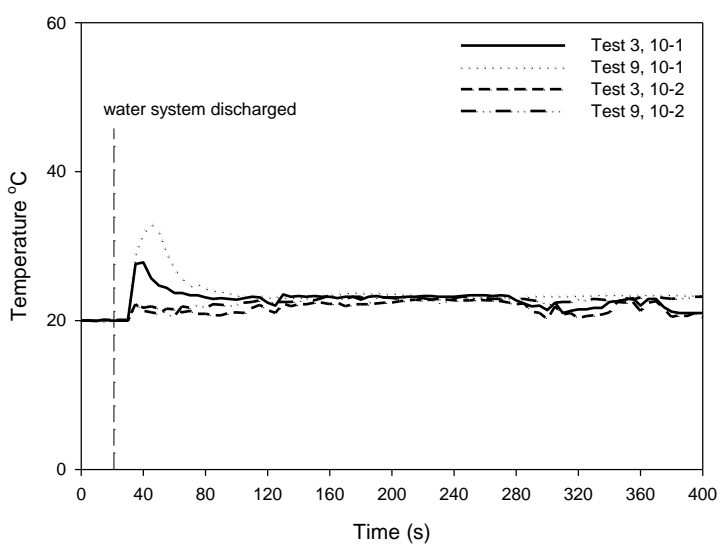

Figure 32. Temperature evolution at positions 10

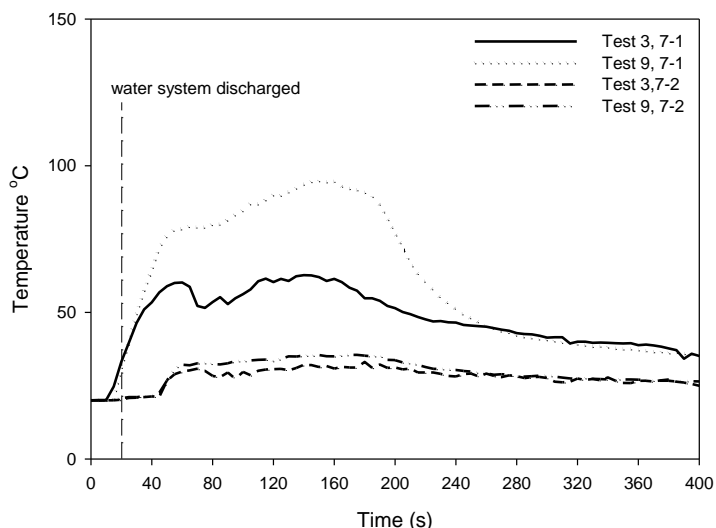

Figure 31. Temperature evolution at positions 7

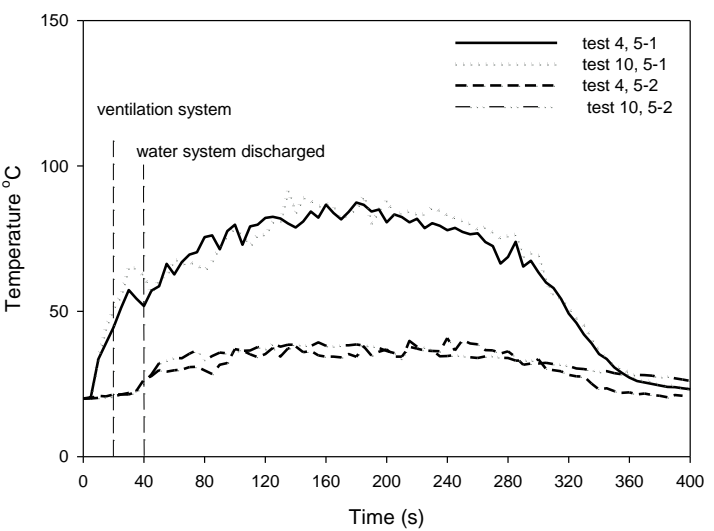

Figure 33. Temperature evolution at positions 5 

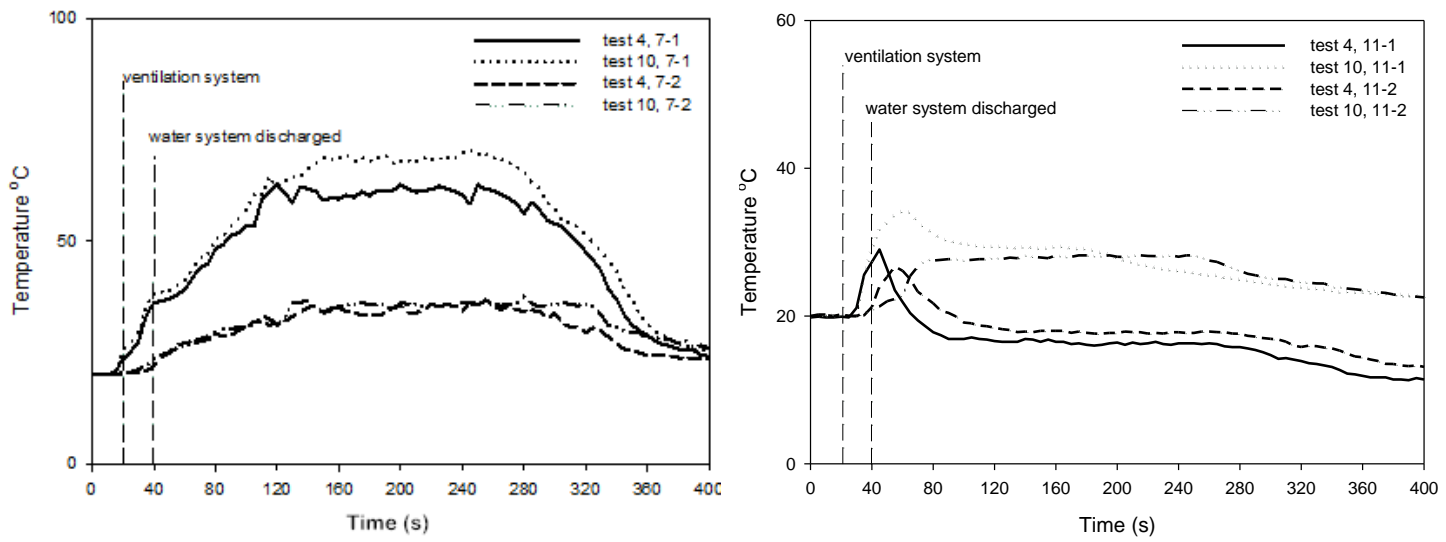

Figure 34. Temperature evolution at positions $7 \quad$ Figure 35. Temperature evolution at positions 11 